\title{
Optical Biomarkers for the Diagnosis of Osteoarthritis through Raman Spectroscopy: Radiological and Biochemical Validation Using Ex Vivo Human Cartilage Samples
}

\author{
Paula Casal-Beiroa ${ }^{1,2}$ (D), Vanesa Balboa-Barreiro ${ }^{3}$, Natividad Oreiro ${ }^{1,2,4}$, Sonia Pértega-Díaz ${ }^{3}$, \\ Francisco J. Blanco $1,2,5, * \mathbb{D}$ and Joana Magalhães $1,2,4, *$ (D)
}

1 Unidad de Medicina Regenerativa, Grupo de Investigación de Reumatología (GIR), Instituto de Investigación Biomédica de A Coruña (INIBIC), Complexo Hospitalario Universitario de A Coruña (CHUAC), SERGAS, Universidade da Coruña (UDC), C/As Xubias de Arriba 84, 15006 A Coruña, Spain; paula.casalb@udc.es (P.C.-B.); natividad.oreiro.villar@sergas.es (N.O.)

2 Centro de Investigaciones Científicas Avanzadas (CICA), Universidade da Coruña (UDC), As Carballeiras S/N, Campus de Elviña, 15071 A Coruña, Spain

3 Unidad de Epidemiología Clínica e Investigación Bioestadística, Instituto de Investigación Biomédica de A Coruña (INIBIC), Complexo Hospitalario Universitario de A Coruña (CHUAC), SERGAS, Universidade da Coruña (UDC), C/As Xubias de Arriba 84, 15006 A Coruña, Spain; vanesa.balboa.barreiro@sergas.es (V.B.-B.); sonia.pertega.diaz@sergas.es (S.P.-D.)

4 Centro de Investigación Biomédica en Red de Bioingeniería, Biomateriales y Nanomedicina (CIBER-BBN), Avenida Monforte de Lemos, 3-5, Pabellón 11, 28029 Madrid, Spain

Citation: Casal-Beiroa, P.; Balboa-Barreiro, V.; Oreiro, N.; Pértega-Díaz, S.; Blanco, F.J.; Magalhães, J. Optical Biomarkers for the Diagnosis of Osteoarthritis through Raman Spectroscopy: Radiological and Biochemical Validation Using Ex Vivo Human Cartilage Samples. Diagnostics 2021, 11, 546. https://doi.org/10.3390/ diagnostics 11030546

Academic Editor: Evangelos Terpos

Received: 7 February 2021

Accepted: 17 March 2021

Published: 18 March 2021

Publisher's Note: MDPI stays neutral with regard to jurisdictional claims in published maps and institutional affiliations.

Copyright: (c) 2021 by the authors. Licensee MDPI, Basel, Switzerland. This article is an open access article distributed under the terms and conditions of the Creative Commons Attribution (CC BY) license (https:/ / creativecommons.org/licenses/by/ $4.0 /)$.
5 Grupo de Investigación de Reumatología y Salud (GIR-S), Departamento de Fisioterapia, Medicina y Ciencias Biomédicas, Facultad de Fisioterapia, Universidade da Coruña (UDC), Campus de Oza, 15008 A Coruña, Spain

* Correspondence: fblagar@sergas.es (F.J.B.); joana.cristina.silva.magalhaes@sergas.es (J.M.)

Abstract: Osteoarthritis (OA) is the most common rheumatic disease, characterized by progressive articular cartilage degradation. Raman spectroscopy (RS) has been recently proposed as a label-free tool to detect molecular changes in musculoskeletal tissues. We used cartilage samples derived from human femoral heads to perform an ex vivo study of different Raman signals and ratios, related to major and minor molecular components of articular cartilage, hereby proposed as candidate optical biomarkers for OA. Validation was performed against the radiological Kellgren-Lawrence (K-L) grading system, as a gold standard, and cross-validated against sulfated glycosaminoglycans (sGAGs) and total collagens (Hyp) biochemical contents. Our results showed a significant decrease in sGAGs (SGAGs, A1063 cm $\mathrm{cm}^{-1} / \mathrm{A} 1004 \mathrm{~cm}^{-1}$ ) and proteoglycans (PGs, A1375 $\mathrm{cm}^{-1} / \mathrm{A} 1004 \mathrm{~cm}^{-1}$ ) and a significant increase in collagen disorganization (ColD/F, A1245 cm-1 $/ \mathrm{A} 1270 \mathrm{~cm}^{-1}$ ), with OA severity. These were correlated with sGAGs or Hyp contents, respectively. Moreover, the SGAGs/HA ratio (A1063 $\mathrm{cm}^{-1} / \mathrm{A} 960 \mathrm{~cm}^{-1}$ ), representing a functional matrix, rich in proteoglycans, to a mineralized matrix-hydroxyapatite (HA), was significantly lower in OA cartilage (K-L I vs. III-IV, $p<0.05$ ), whilst the mineralized to collagenous matrix ratio (HA/Col, A960 $\mathrm{cm}^{-1} / \mathrm{A} 920 \mathrm{~cm}^{-1}$ ) increased, being correlated with K-L. OA samples showed signs of tissue mineralization, supported by the presence of calcium crystals-related signals, such as phosphate, carbonate, and calcium pyrophosphate dihydrate (MGP, A960 cm $\mathrm{cm}^{-1} / \mathrm{A} 1004 \mathrm{~cm}^{-1}$, MGC, A1070 $\mathrm{cm}^{-1} / \mathrm{A} 1004 \mathrm{~cm}^{-1}$ and A1050 $\mathrm{cm}^{-1} / \mathrm{A} 1004 \mathrm{~cm}^{-1}$ ). Finally, we observed an increase in lipids ratio (IL, A1450 $\mathrm{cm}^{-1} / \mathrm{A} 1670 \mathrm{~cm}^{-1}$ ) with OA severity. As a conclusion, we have described the molecular fingerprint of hip cartilage, validating a panel of optical biomarkers and the potential of RS as a complementary diagnostic tool for OA.

Keywords: optical biomarkers; osteoarthritis; K-L grade; glycosaminoglycans; total collagen; lipids; calcium crystals 


\section{Introduction}

Osteoarthritis (OA) is a multifactorial disease that affects movable joints and one of the main causes of disability worldwide. It manifests as a set of molecular imbalances followed by physiologic and anatomical alterations of the joint tissues, such as articular cartilage extracellular matrix (ECM) degradation, subchondral sclerosis, and inflammation of the synovial membrane, which culminate in illness [1-3].

In its early stages, OA is asymptomatic, which hinders its prompt clinical diagnosis. In order to clinically assess a patient, pain and mobility questionnaires are performed, followed by radiography, and in some cases magnetic resonance imaging (MRI), which allows classification according to OA severity, under different scoring systems [4]. Even though these imaging techniques are routinely used for OA diagnosis, they present several disadvantages. On one hand, X-ray analysis is based on the observation of adjacent bone surface irregularities and remodeling, which limits its scope from moderate to advanced OA. On the other, MRI's high cost and incompatibility for some patients, limits its application as a regular medical care practice [5]. Together with other unmet needs for successful diagnosis and treatment, these have spurred the investigation on biomarkers discovery and validation [6].

Raman spectroscopy (RS) is an optical technique that allows obtaining compositional information at the molecular level, being a non-invasive and label-free method [7]. It is based on the inelastic scattering that occurs when a monochromatic light interacts with the tissue sample analyzed, producing energy variations between the incident radiation with respect to the reflected. This Raman scattering is characteristic and specific of a vibrational mode, bond, or molecule present in the tissue composition, producing an unique molecular fingerprint [8]. Typical Raman spectra are displayed at different intensities with corresponding wavelength shifts $\left(\mathrm{cm}^{-1}\right)$ specific to molecular vibrations. Thereafter, raw data is processed and can be classified according to unsupervised or supervised statistical methods, allowing sample classification and diagnostic analysis [7].

Recently, RS has been explored in different rheumatologic diseases, including OA, covering different joint tissues, including articular cartilage, synovium, bone, and to a less extent, the meniscus, tendons, and ligaments. For each individual tissue, a set of optical biomarker candidates for OA has been proposed, further supporting RS potential as a diagnostic method [9-14].

Since the first analysis of human articular cartilage by RS [15], several authors have reported differences found in specific Raman peaks or ratios related to major ECM components that can be associated to molecular events that occur during OA progression. Such changes can be summarized in alterations on the relative distribution of the collagen secondary structure (amide III, C-N stretching, random coil and $\alpha$-helix, at 1245 and $1270 \mathrm{~cm}^{-1}$, respectively) [16-18], and the decrease of sulphated glycosaminoglycans (GAGs) content $\left(\mathrm{OSO}_{3}{ }^{-}\right.$symmetric stretching, at $\left.1063 \mathrm{~cm}^{-1}\right)[15,18]$. Additionally, studies reported the presence of phosphate and carbonate hydroxyapatite peaks $\left(\sim 958 \mathrm{~cm}^{-1}\right.$ and $\sim 1070 \mathrm{~cm}^{-1}$, respectively) in injured cartilage and hypertrophic zones [15,19]. The occurrence of tissue mineralization and remodeling processes have also been associated with the presence of the aforementioned Raman peaks, in damaged tissues, on an OA rat model [20].

So far, RS studies on OA cartilage have covered different anatomical areas of the joint (tibial plateau and femoral condyle) $[17,18,21]$ but few have referenced histopathological scoring systems (e.g., the Collins pathological scale) [17]; even on the cellular level, only one study used chondrocytes isolated from different OA stages, based on the International Cartilage Repair Society (ICRS) system [18]. In overall, sample sizes used are limited and there is a lack of validation against clinical gold standards or cross-validation against biochemical tools $[17,22]$.

In this work, we propose to study the molecular alterations on human cartilage derived from the femoral heads of a cohort of forty-seven healthy and radiological OA patients, cross-validated against biochemical assays for sulfated-GAGs (sGAGs) and total 
collagen (Hyp). Raman spectroscopy is further proposed as a complementary diagnostic tool for OA, through the validation of optical biomarkers.

\section{Materials and Methods}

\subsection{Study Cohort and Sample Collection}

Human articular cartilage samples (plugs of $6 \mathrm{~mm}$ diameter and $\sim 1$ to $1.5 \mathrm{~mm}$ thick) were extracted from the femoral head of 47 donors, $24-48 \mathrm{~h}$, after joint replacement intervention, frozen in liquid nitrogen and stored at $-80^{\circ} \mathrm{C}$, until further processing. The inclusion factor was samples from patients with available index femoral head radiography for the assessment of OA severity, by clinical doctors, according to the Kellgren-Lawrence (K-L) grading scale as follows: grade 0: no pathological features; grade I: doubtful narrowing of joint space and possible osteophytic lipping; grade II: definite osteophytes and possible narrowing of joint space; grade III: moderate multiple osteophytes, definite narrowing of joint space, some sclerosis, and possible deformity of bony ends, and grade IV: large osteophytes, marked narrowing of joint space, severe sclerosis, and definite deformity of bone ends [5]. Six donors were thus classified as healthy $(\mathrm{K}-\mathrm{L}=0)$ and forty-one as OA (K-L $\geq \mathrm{I}-\mathrm{IV})$. The final cohort (Table 1 ) was composed of cartilage samples from donors aged between 42 and 94 years (mean age of 72), with a female/male ratio close to 3:2.

Table 1. Demographics and clinical diagnostic of the patients included in this study.

\begin{tabular}{cccc}
\hline \multicolumn{3}{c}{ Demographics } & \\
\hline \multirow{2}{*}{ Sex } & Female (F) & $n=27$ & $57.4 \%$ \\
& Male (M) & $n=20$ & $42.6 \%$ \\
\hline \multirow{2}{*}{ Age } & Range & $42-94$ years old \\
& Mean \pm SD & $72 \pm 12$ years old \\
\hline \multirow{2}{*}{ Radiological grade (K-L) } & Diagnostic & \\
& Healthy (K-L 0) & $n=6$ \\
& OA (K-L I-IV) & $n=41$ \\
\hline
\end{tabular}

\subsection{Raman Spectra Obtainment and Data Processing}

Raman spectra were collected from the surface of cartilage samples using a WITec Alpha300R+ Raman spectrometer (WITec focus innovations, Ulm, Germany), equipped with a Near-Infrared (NIR) laser $(\lambda=785 \mathrm{~nm})$ with incident laser radiation of $50 \mathrm{~mW}$, 120 scans, $4 \mathrm{~cm}^{-1}$ resolution and an acquisition time of $1 \mathrm{~s}$, to achieve a good signal-tonoise ratio. Once spectra were acquired, baseline correction and analysis were carried out using MagicPlot version 2.7 software (Magic Plot Systems, LLC). Briefly, linear baseline correction was performed by limiting the selected wavenumber intervals, related with the biochemical vibrations of interest. Peaks' assignment was then performed based on available literature. For a quantitative analysis, the main peaks were integrated based on a Gaussian distribution, adjusting the areas' sum to the spectral profile in order to predict signals' overlaps. An example of the area measurement in an arbitrary spectrum is presented as supplementary material (Figure S1). Proposed optical biomarkers (Table 2) were calculated based on the peaks' area values, and a relative quantification was performed using phenylalanine (Phe) $\left(1004 \mathrm{~cm}^{-1}\right)$, as normalization peak $[15,16,18,19]$. 
Table 2. Optical biomarker candidates for osteoarthritis (OA) in human cartilage derived from the femoral head.

\begin{tabular}{|c|c|c|c|}
\hline Optical Biomarker & $\begin{array}{l}\text { Molecular Component or } \\
\text { Associated Event }\end{array}$ & Acronym & Definition \\
\hline A960 $\mathrm{cm}^{-1} / \mathrm{A} 1004 \mathrm{~cm}^{-1}$ & Mineralization-Phosphate Groups & MGP & $\begin{array}{l}\text { Phosphate groups present } \\
\text { at hydroxyapatite }\end{array}$ \\
\hline A960 $\mathrm{cm}^{-1} /$ A920 $\mathrm{cm}^{-1}$ & $\begin{array}{c}\text { Phosphate } \\
\text { Hydroxyapatite/Collagen }\end{array}$ & $\mathrm{HA} / \mathrm{Col}$ & Bone to collagen \\
\hline A1039-42 $\mathrm{cm}^{-1} / \mathrm{A} 1004 \mathrm{~cm}^{-1}$ & Total GAGs & TGAGs & Total glycosaminoglycans \\
\hline A1050 cm $\mathrm{cm}^{-1} / \mathrm{A} 1004 \mathrm{~cm}^{-1}$ & CPPD & CPPD & $\begin{array}{l}\text { Calcium pyrophosphate } \\
\text { dihydrate deposits }\end{array}$ \\
\hline A1063 $\mathrm{cm}^{-1} / \mathrm{A} 1004 \mathrm{~cm}^{-1}$ & Sulphated GAGs & SGAGs & $\begin{array}{l}\text { Sulphated glycosaminoglycans } \\
\left(\mathrm{OSO}_{3}-\text { groups }\right)\end{array}$ \\
\hline A1063 $\mathrm{cm}^{-1} /$ A960 $\mathrm{cm}^{-1}$ & Sulphated GAGs/Phosphate & SGAGs/HA & Cartilage to bone \\
\hline A1070 $\mathrm{cm}^{-1} / \mathrm{A} 1004 \mathrm{~cm}^{-1}$ & Mineralization-Carbonate Groups & MGC & $\begin{array}{l}\text { Mineralization grade-carbonated } \\
\text { hydroxyapatite }\end{array}$ \\
\hline A1245 $\mathrm{cm}^{-1} / \mathrm{A} 1270 \mathrm{~cm}^{-1}$ & Defective/Functional Collagen & ColD/F & $\begin{array}{l}\text { Collagen randomness-as the } \\
\text { relative amount of collagen random } \\
\text { coil (defective Col) to an } \alpha \text {-helix } \\
\text { structure (functional Col) }\end{array}$ \\
\hline A1375 $\mathrm{cm}^{-1} / \mathrm{A} 1004 \mathrm{~cm}^{-1}$ & Proteoglycans & PGs & Proteoglycans \\
\hline A1450 $\mathrm{cm}^{-1} / \mathrm{A} 1668 \mathrm{~cm}^{-1}$ & Indirect Lipid Index & IL & $\begin{array}{l}\text { Relative amount of unspecific lipids } \\
\text { and proteins to the total } \\
\text { protein content }\end{array}$ \\
\hline
\end{tabular}

$1004 \mathrm{~cm}^{-1}$, Phenylalanine (Phe) peak used for normalization.

\section{3. sGAGs and Total Collagen Biochemical Content Analysis}

After RS analysis, cartilage samples were frozen at $-80^{\circ} \mathrm{C}$ and lyophilized in a Telstar Cryodos (Telstar, Barcelona, Spain), at $-0.1 \mathrm{mbar}$, for $18 \mathrm{~h}$. Explants (10-50 mg) were digested with papain $\left(2.5 \times 10^{-2} \mathrm{mg} / \mathrm{mL}\right)$ in $0.2 \mathrm{M}$ sodium phosphate buffer $\left(\mathrm{Na}_{2} \mathrm{HPO}_{4}{ }^{-} \mathrm{NaH}_{2} \mathrm{PO}_{4}, \mathrm{pH} 6.4\right), 8 \mathrm{mg} / \mathrm{mL}$ sodium acetate, $4 \mathrm{mg} / \mathrm{mL}$ EDTA and $0.8 \mathrm{mg} / \mathrm{mL}$ L-cysteine- $\mathrm{HCl}$ (all from Sigma-Aldrich, Darmstadt, Germany), at $65^{\circ} \mathrm{C}$, for $18 \mathrm{~h}$. The amount of sulfated GAGs (sGAGs) was quantified using the dimethyl methylene blue (DMMB) dye-binding assay (Blyscan, Biocolor Ltd., Carrickfergus, UK) with a chondroitin sulphate standard and normalized against the explants' wet weight (w.wt). For the quantification of total collagen, an acid hydrolysis of the digested supernatant was performed, by adding $\mathrm{HCl}$ 37\% (Panreac AppliChem, Darmstadt, Germany) at a ratio of 1:1, in Teflonsealed borosilicate glass vials (Lab Logistics Group, Meckenheim, Germany), at $120^{\circ} \mathrm{C}$, for $18 \mathrm{~h}$. The total collagen content was then measured using the hydroxyproline ( $\mathrm{Hyp}$ ) assay kit (Sigma-Aldrich, Darmstadt, Germany) with hydroxyproline standards and normalized against each sample' w.wt. Both sGAGs and Hyp absorbance readings were carried out for each cartilage sample in duplicate, in 96-well plates, at $656 \mathrm{~nm}$ or $560 \mathrm{~nm}$, respectively, using a Sinergy HTX reader (BioTek, Winooski, VT, USA).

\subsection{Statistical Analysis}

All statistical analyses were carried out using R statistical open software (version R 3.5.1). Kruskal-Wallis non-parametric tests with Bonferroni correction were performed. Spearman's correlation coefficients rho were determined in order to compare the proposed biomarkers versus radiological K-L grade or biochemical parameters, sGAGs and Hyp. All values are reported \pm as means standard deviation (SD). Significance was accepted at a level of $p<0.05$. 


\section{Results}

\subsection{Molecular Alterations during Radiological OA Progression-Raman Spectra Analysis}

Raman spectra in the $800-1800 \mathrm{~cm}^{-1}$ region, of human cartilage explants, derived from healthy donors (K-L 0) and patients with different radiological OA grading (K-L I to IV) were depicted in Figure 1.

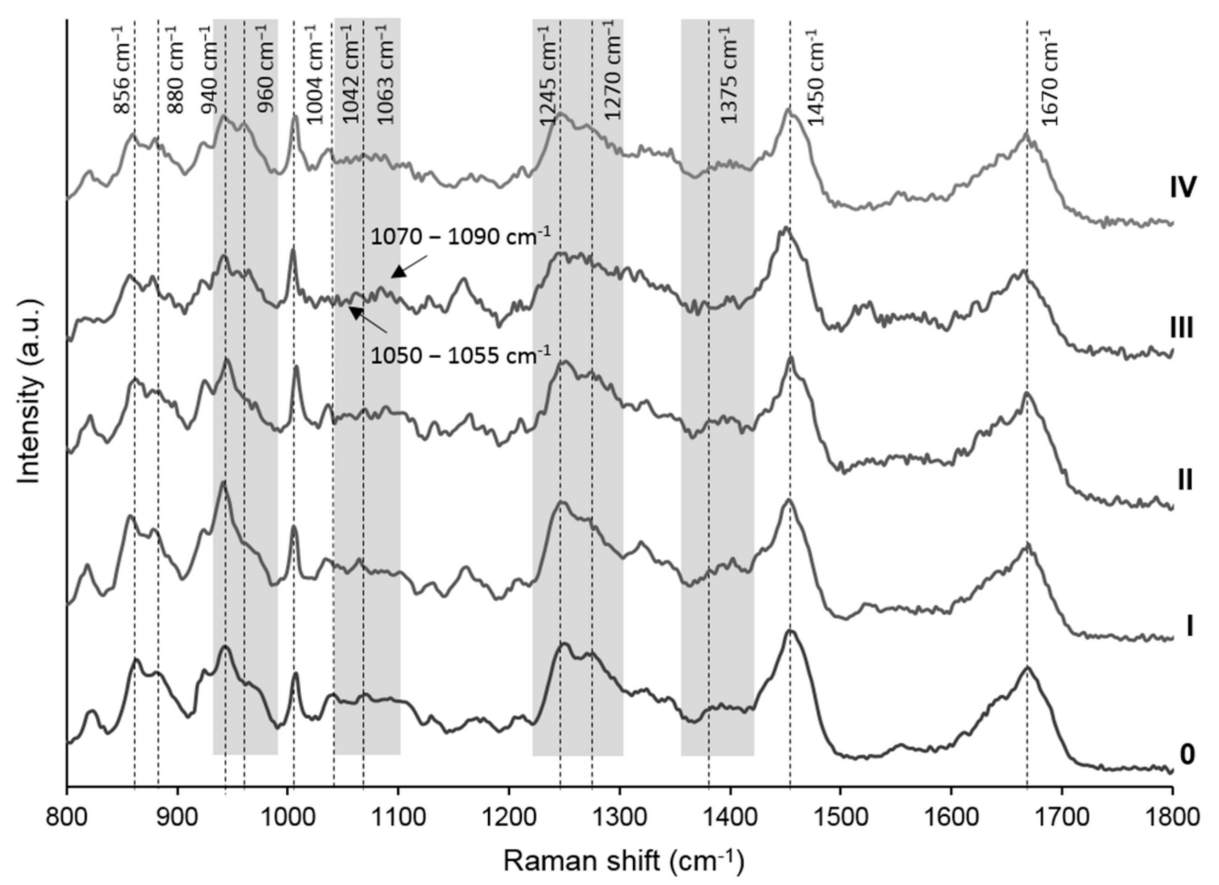

Figure 1. Raman spectra obtained from cartilage explants derived from the femoral heads of patients with different Kellgren-Lawrence (K-L) radiological OA severity grades (0-IV), obtained at a $\lambda=785 \mathrm{~nm}$ with incident laser radiation of $50 \mathrm{~mW}, 120$ scans, $4 \mathrm{~cm}^{-1}$ resolution and $1 \mathrm{~s}$ acquisition time.

The main peaks identified, summarized in Table 3, were those obtained at Raman shifts as follows: $850-880 \mathrm{~cm}^{-1}$, corresponding to the C-C bond stretching of proline (Pro) and hydroxyproline (Hyp) [16,23]; 920-928 $\mathrm{cm}^{-1}$, corresponding to the C-C stretching of proline [16]; $940 \mathrm{~cm}^{-1}$, corresponding to both the symmetric stretching mode of the O-glycosidic bond and the protein C-C stretching $[19,23,24] ; 1004 \mathrm{~cm}^{-1}$, corresponding to the aromatic ring stretching of phenylalanine (Phe) [15]; $1042 \mathrm{~cm}^{-1}$, assigned to the $\mathrm{C}-\mathrm{O}-\mathrm{C}$ stretching, of the pyranose ring of GAGs [23]; $1063 \mathrm{~cm}^{-1}$, assigned to the symmetric stretching of ${\mathrm{O}-\mathrm{SO}_{3}}^{-}$of sulfated GAGs $[15,18,19,23] ; 1245-1270 \mathrm{~cm}^{-1}$ doublet, corresponding to the $\mathrm{C}-\mathrm{N}$ stretching of amide III, random coil or $\alpha$-helix structure of collagen, respectively [17]; $1375 \mathrm{~cm}^{-1}$, corresponding to the symmetric stretching of the methyl $\left(-\mathrm{CH}_{3}\right)$ group, related to proteoglycans (PGs) [21]; $1450 \mathrm{~cm}^{-1}$, corresponding to the vibrational deformation modes $\left(\mathrm{CH}_{2}\right)$, from lipids and proteins, and $\sim 1670 \mathrm{~cm}^{-1}$, assigned to $\mathrm{C}=\mathrm{O}$ stretching of amide I, present in collagen and other proteins $[15,16,19]$. 
Table 3. Raman peaks assignments of articular cartilage molecular fingerprint, obtained from healthy and radiological OA tissues.

\begin{tabular}{|c|c|c|c|}
\hline Raman Shift (cm-1) & $\begin{array}{l}\text { Assigned Bond/ } \\
\text { Molecule }\end{array}$ & Component & References \\
\hline $850-880$ & $\mathrm{C}-\mathrm{C}$ stretching & \multirow{3}{*}{ Collagen } & \multirow{3}{*}[16,23]{} \\
\hline $856-858$ & Pro & & \\
\hline $875-880$ & Hyp & & \\
\hline $920-928$ & C-C stretching Pro & Collagen & {$[15,16]$} \\
\hline $932-941$ & Symmetric stretching: & \multirow{3}{*}{$\begin{array}{l}\text { Collagen } \\
\text { GAGs }\end{array}$} & \multirow{3}{*}[16,19,23,24]{} \\
\hline $932-938$ & $\mathrm{C}-\mathrm{C}$ protein backbone & & \\
\hline $937-941$ & $\mathrm{C}-\mathrm{O}-\mathrm{C} \propto 1-4$ glycosidic bond & & \\
\hline $954-962$ & $\mathrm{PO}_{4}{ }^{3-}$, symmetric stretching & Phosphate hydroxyapatite (HA) & {$[15,19,23,25,26]$} \\
\hline 1004 & $\begin{array}{l}\text { Aromatic ring stretching } \\
\text { phenylalanine }(P h e)\end{array}$ & Proteins & {$[15,16,19]$} \\
\hline $1039-1042$ & $\begin{array}{l}\mathrm{C}-\mathrm{O}-\mathrm{C} \text { stretching } \\
\text { pyranose ring }\end{array}$ & GAGs & [23] \\
\hline $1047-1055$ & P-O-P symmetric stretching & CPPD & [27] \\
\hline $1060-1064$ & $\mathrm{O}_{-} \mathrm{SO}_{3}{ }^{-}$symmetric stretching & Sulphated GAGs, PGs & {$[15,19,21,23,28]$} \\
\hline $1070-1090$ & $\mathrm{CO}_{3}{ }^{2-}$, asymmetric stretching & Carbonate & \multirow{4}{*}[15,21,24,25,29]{} \\
\hline $1070-1073$ & Type-B carbonate & Carbonated hydroxyapatite & \\
\hline $1080-1082$ & Amorphous carbonate & Amorphous carbonate & \\
\hline 1090 & $\mathrm{CaCO}_{3}$ & Calcium carbonate deposits & \\
\hline $1230-1280$ & C-N stretching amide III: & Collagen: & \multirow{3}{*}[16-18,21,23]{} \\
\hline 1245 & random coil & Defective & \\
\hline 1270 & $\alpha$-helix structure & Functional & \\
\hline $1375-1380$ & $\mathrm{CH}_{3}$ symmetric stretching & GAGs, PGs & [21] \\
\hline $1441-1460$ & $\mathrm{CH}_{2}$ deformation/scissoring & Protein and lipids & {$[15,16]$} \\
\hline $1630-1690$ & $\mathrm{C}=\mathrm{O}$ stretching amide $\mathrm{I}$ : & \multirow{4}{*}{ Collagen and other proteins } & \multirow{4}{*}[15,16,19]{} \\
\hline $1645-1655$ & $\alpha$-helix structure & & \\
\hline $1660-1670$ & random coil & & \\
\hline $1665-1675$ & $\beta$-sheet structure & & \\
\hline $1550-1600$ & $\mathrm{~N}-\mathrm{H}$ and $\mathrm{C}-\mathrm{N}$ deformation amide II & Proteins & {$[24]$} \\
\hline
\end{tabular}

Several differences between healthy and OA cartilage Raman spectra were observed. For a better comprehension, Figure 2 shows different regions of interest (ROI) and corresponding peaks deconvolution. Grossly, concerning collagen, it was observed a decrease in the $1270 \mathrm{~cm}^{-1}$ peak, related to a $\alpha$-helix secondary structure, with respect to $\sim 1245 \mathrm{~cm}^{-1}$, related to collagen's random coil configuration (Figure 2A,B) [17,18]. A decrease in peaks related to PGs (1063 and $1375 \mathrm{~cm}^{-1}$ ) [21], in severely damaged cartilage (K-L IV) was observed (Figure 2C,D).

Moreover, the appearance or increase of peaks related to mineralization was observed in OA cartilage. Different types of inorganic components were found, such as carbonate compounds in the $1060-1100 \mathrm{~cm}^{-1}$ region (Figure 2C,D, Table 3) and calcium pyrophosphate dehydrate deposits (CPP), in the $1020-1055 \mathrm{~cm}^{-1}$ region (Figure 2E,F, Table 3) [27]. An overlap of the carbonated hydroxyapatite peak (type-B carbonate, $1070 \mathrm{~cm}^{-1}$ ) [21] with the $1063 \mathrm{~cm}^{-1}$ peak, correspondent to sulfate groups could be observed. Other carbonate related peaks detected, in OA cartilage (Figure 2D), could be related with amorphous carbonate $\left(\sim 1080 \mathrm{~cm}^{-1}\right)$ and crystalline carbonate compounds, as calcium carbonate $\left(\sim 1090 \mathrm{~cm}^{-1}\right)[15,21,25,29-31]$. Moreover, an increase of the $\sim 960 \mathrm{~cm}^{-1}$ peak, from hydroxyapatite phosphate groups, can be associated with tissue mineralization during OA progression (Figure 2G,H) $[18,19,25,26]$. 

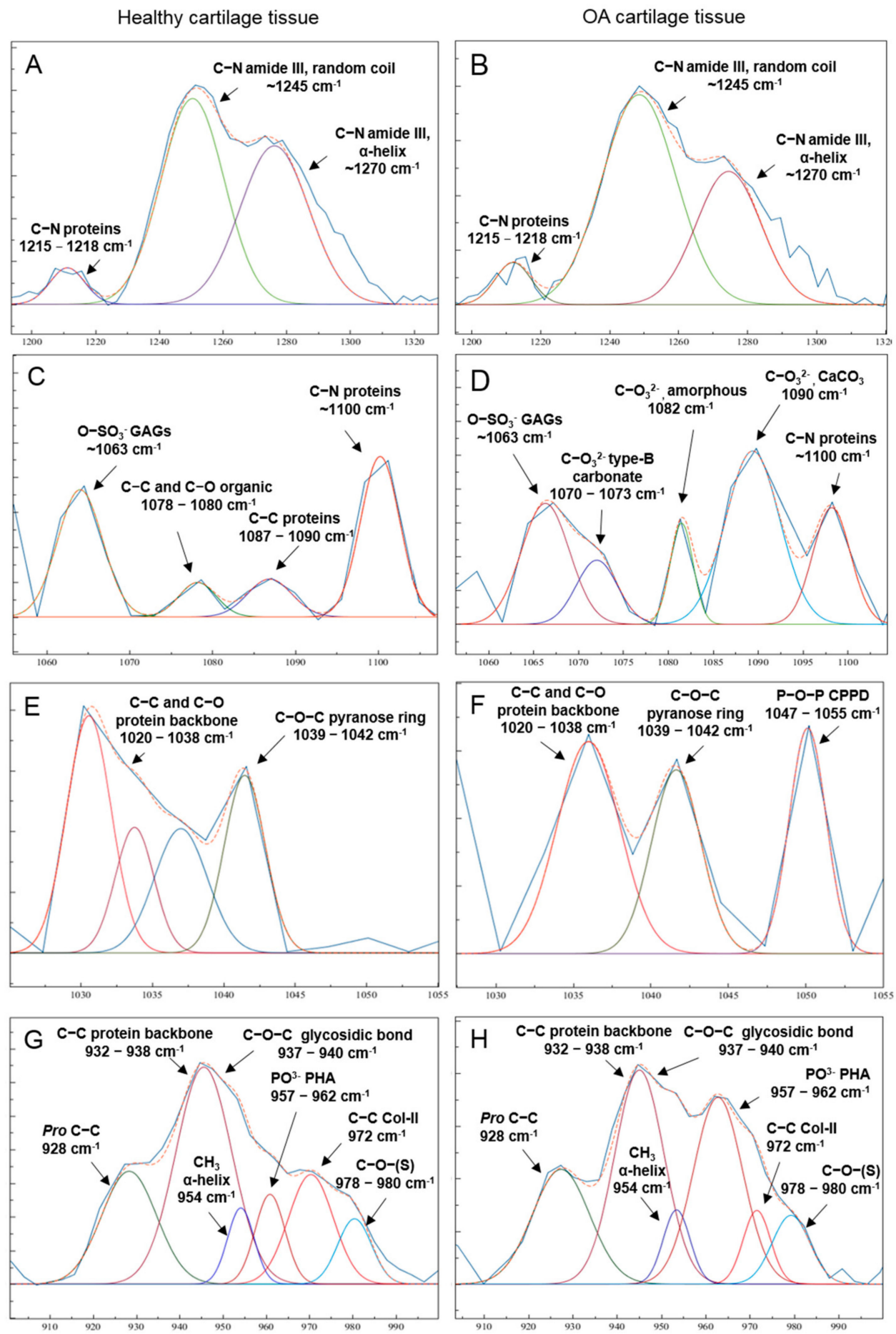

Figure 2. Deconvolution of peaks of the principal molecular alterations observed in healthy (K-L 0 , left column) and radiological OA (K-L IV, right column) cartilage. Regions of interest (ROI) are depicted as follows, (A,B) 1200-1300 cm $\mathrm{cm}^{-1}$; (C,D) 1060-1100 cm $\mathrm{cm}^{-1}$; (E,F) 1020-1055 cm ${ }^{-1}$; (G,H) 900-1000 $\mathrm{cm}^{-1}$.

\subsection{Molecular Alterations during OA Progression-K-L Validation}

Ratios related to glycosaminoglycans, i.e., "sulphated GAGs" (SGAGs, A1063 cm-1/ A1004 cm ${ }^{-1}$ ), "total GAGs" (TGAGs, A1042 cm ch $^{-1}$ A1004 cm cm $^{-1}$ ) and "PGs" (A1375 cm ${ }^{-1} /$ A1004 $\mathrm{cm}^{-1}$ ), showed a decrease with increasing K-L grade (Figure 3). Among these parameters, only SGAGs and PGs showed statistically significant differences, detected between healthy and doubtful OA (K-L 0-I grades) with mild to severe OA (K-L II-IV 
grades) as follows, K-L 0 vs. K-L II and IV ( $p<0.05)$ and K-L I vs. K-L II-IV $(p<0.01)$, K-L $0-\mathrm{I}$ vs. K-L III $(p<0.05)$, respectively. These results were supported by negative correlations obtained for SGAGs $(r h o=-0.632, p<0.001)$, PGs $(r h o=-0.532, p<0.001)$ and TGAGs $($ rho $=-0.324, p=0.025)$ (Table 4$)$.

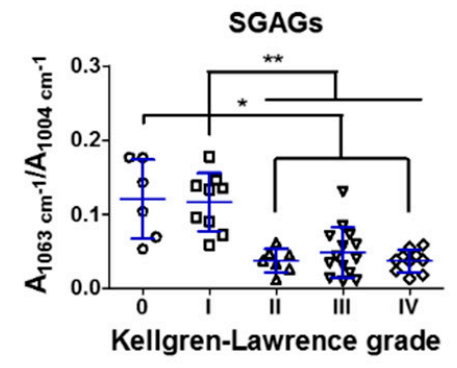

PGs

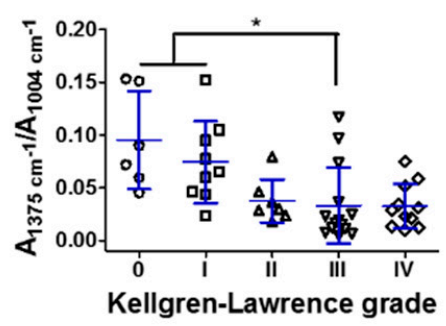

IL
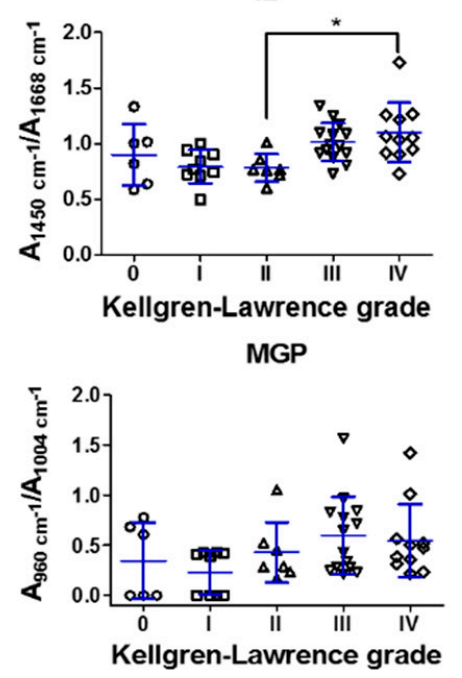

SGAGs/HA

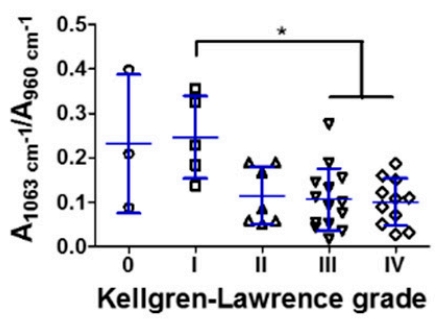

TGAGs

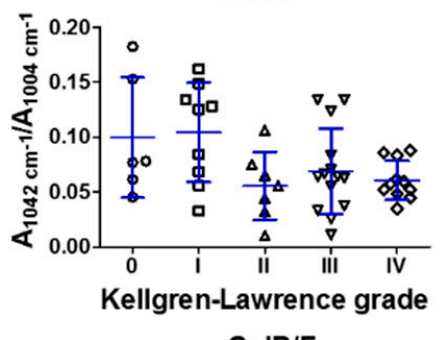

CoID/F
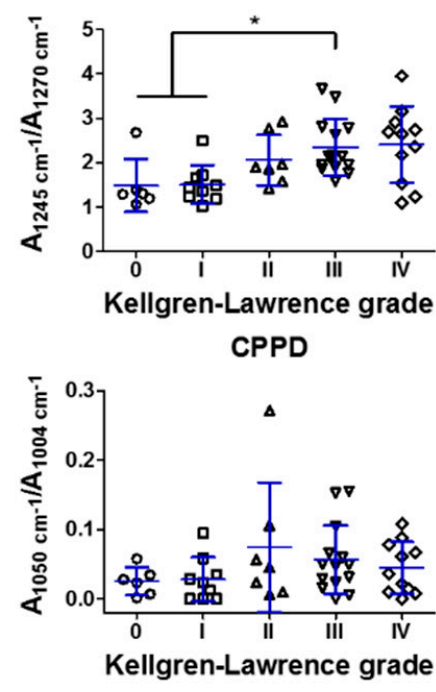

MGC

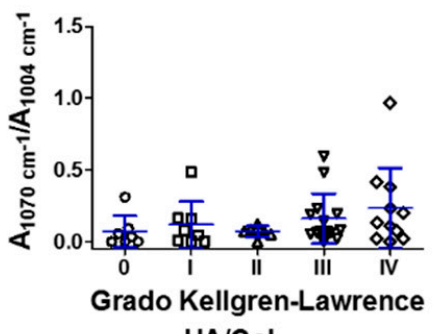

HA/Col

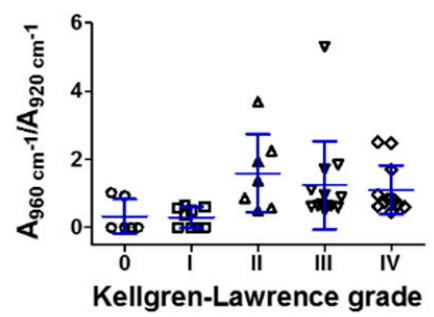

Figure 3. Quantitative results of Raman ratios related to cartilage components, glycosaminoglycans (SGAGs, TGAGs, PGs), collagen (ColD/F), lipids (IL) and tissue mineralization (directly related: CPPD, MGP, MGC and indirectly related: SGAGs/HA and HA/Col) of cartilage, derived from the femoral head, of healthy (K-L 0) and radiological OA (K-L I-IV) patients. Values are mean \pm SD. Symbols $(\Delta, \square, \circ, \diamond)$ represent individual samples. Significance is indicated as ${ }^{*} p<0.05$ and ** $p<0.01$. 
Table 4. Spearman's rho coefficients and $p$-values for proposed Raman biomarkers and Kellgren-Lawrence (K-L) grading system. Significance was considered for $p<0.05$.

\begin{tabular}{ccccccccccc}
\hline & SGAGs & TGAGs & PGs & ColD/F & IL & CPPD & MGP & MGC & SGAGs/HA & HA/Col \\
\hline rho & -0.632 & -0.324 & -0.532 & 0.529 & 0.427 & 0.191 & 0.321 & 0.293 & -0.426 & 0.446 \\
$p$ & $<0.001$ & 0.025 & $<0.001$ & $<0.001$ & 0.002 & 0.219 & 0.260 & 0.043 & 0.005 & 0.001 \\
\hline
\end{tabular}

Regarding the parameter related to the configuration of collagen fibers, "Defective/Functional Collagen" ratio (ColD/F, A1245 $\mathrm{cm}^{-1} / \mathrm{A} 1270 \mathrm{~cm}^{-1}$ ) increased with OA severity, obtaining significant differences between K-L 0-I vs. K-L III $(p<0.05)$ (Figure 3), supported by a positive correlation ( $r h o=0.529, p<0.001)$ (Table 4$)$.

The "Indirect Lipid index" ratio (IL, A1450 $\mathrm{cm}^{-1} / \mathrm{A} 1668 \mathrm{~cm}^{-1}$ ) showed an increasing trend, with significant differences found only between mild and severe radiological OA (K-L II vs. IV, $p<0.05$ ) (Figure 3) and a correlation with K-L ( $r h o=0.427, p=0.002)$ (Table 4).

For parameters directly related with tissue mineralization, i.e., "Mineralization —Phosphate Groups" (MGP, A960 $\mathrm{cm}^{-1} / \mathrm{A} 1004 \mathrm{~cm}^{-1}$ ), "Mineralization-Carbonate Groups" (MGC, A1070 $\mathrm{cm}^{-1} / \mathrm{A} 1004 \mathrm{~cm}^{-1}$ ), "calcium pyrophosphate dihydrate deposits" (CPPD, A1050 $\mathrm{cm}^{-1} / \mathrm{A} 1004 \mathrm{~cm}^{-1}$ ), we found an increasing trend, in regard with OA severity, for both MGP and MGC parameters, whilst CPPD presented higher variability (Figure 3). A weak correlation was found for MGC $(r h o=0.293, p=0.043)$ (Table 4$)$.

On the other hand, for indirectly related mineralization parameters, an increasing trend with OA severity was found for "Phosphate Hydroxyapatite/Collagen" ratio (HA/Col, A960 $\mathrm{cm}^{-1} / \mathrm{A} 920 \mathrm{~cm}^{-1}$ ) (Figure 3), indicative of the relative amount of mineralized tissue in regard to a collagenous matrix [15], supported by a positive correlation ( $r h o=0.446, p=0.001)$ (Table 4). An opposite behavior was found in the SGAGs/HA ratio (A1063 $\mathrm{cm}^{-1} / \mathrm{A} 960 \mathrm{~cm}^{-1}$ ), indicative of the relative amount of functional extracellular matrix, rich in GAGs, with respect to the mineralized matrix [15], with significant differences between K-L I and K-L III-IV $(p<0.05)$ (Figure 3$)$ and a negative correlation $(r h o=-0.426$, $p=0.005)($ Table 4$)$.

\subsection{Molecular Alterations during OA Progression-Biochemical Cross-Validation}

The sGAGs content obtained biochemically was observed to significantly decrease with the progression of cartilage degradation, from values of $41.10 \pm 10.52$ (K-L I) to $26.49 \pm 12.42$ (K-L II) and $29.69 \pm 11.16 \mu \mathrm{g} / \mathrm{mg}$ w.wt (K-L III) (both $p<0.05$ ) and $24.26 \pm 10.68 \mu \mathrm{g} / \mathrm{mg}$ w.wt (K-L IV, $p<0.01$ ) (Figure 4A). This finding is consistent with a decrease observed in the proposed Raman biomarkers related with GAGs and PGs (Figure 2).

A

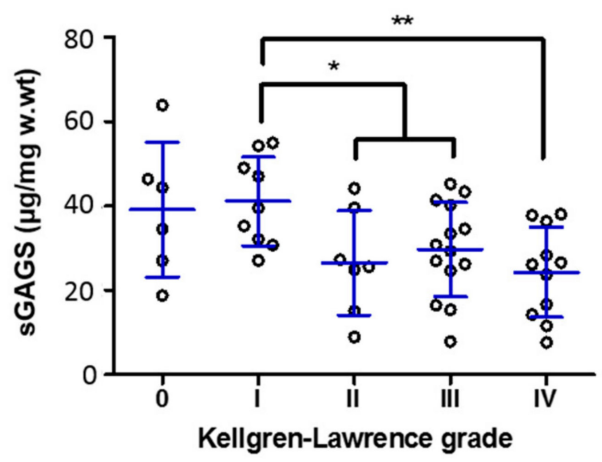

B

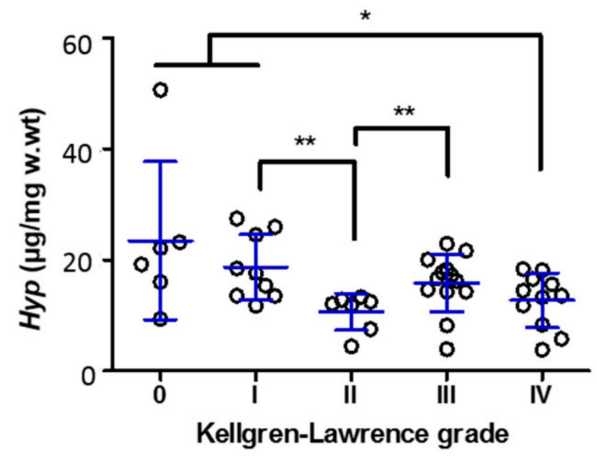

Figure 4. Biochemical content of sGAGs (A) and total collagens (Hyp) (B) of articular cartilage with different Kellgren-Lawrence (K-L) grades. Values are mean \pm SD. Dots represent individual samples. Significance is indicated as ${ }^{*} p<0.05$ and ${ }^{* *} p<0.01$. 
Furthermore, sGAGs content was found to be positively correlated with the Raman parameters SGAGs (A1063 $\mathrm{cm}^{-\mathrm{c}} / 1004 \mathrm{~cm}^{-1}$ ) and PGs (A1375 $\mathrm{cm}^{-} / 1004 \mathrm{~cm}^{-1}$ ), obtaining a higher value for SGAGs, which is directly related to sulphate groups ( $r h o=0.6830)$, when compared with PGs $(r h o=0.5952)$ (both $p<0.0001)$ (Figure 5). No significant correlation was detected between sGAGs biochemical content and the TGAGs parameter $(r h o=0.2659$, $p=0.075)$ (data not shown).
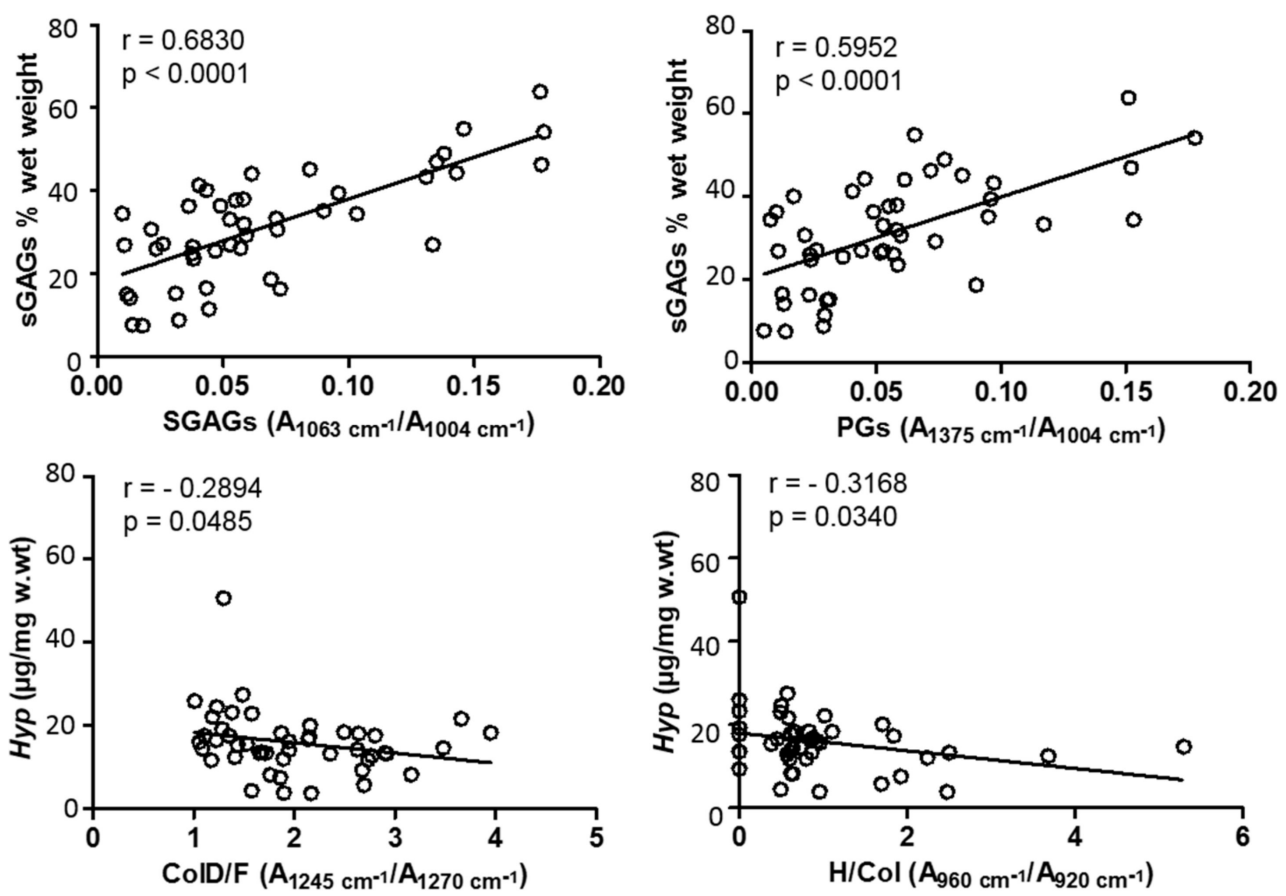

Figure 5. Correlations obtained between sGAGs and total collagens (Hyp) biochemical content and related optical biomarkers, SGAGs (A1063 $\mathrm{cm}^{-1} / 1004 \mathrm{~cm}^{-1}$ ) and PGs (A1375 $\mathrm{cm}^{-1} / 1004 \mathrm{~cm}^{-1}$ ), and ColD/F (A1425 $\left.\mathrm{cm}^{-1} / 1270 \mathrm{~cm}^{-1}\right)$ and H/Col $\left(\right.$ A960 $\left.\mathrm{cm}^{-1} / 920 \mathrm{~cm}^{-1}\right)$, respectively. Spearman's rho coefficients and $p$-values are indicated. Significance was considered for $p<0.05$.

Regarding total collagens content obtained biochemically, a significant decrease was observed with OA severity, namely, K-L 0 and I vs. K-L IV (Hyp = 23.47 \pm 14.2 and $18.71 \pm 5.81$ vs. $12.71 \pm 4.87 \mu \mathrm{g} / \mathrm{mg}$ w.wt, $p<0.05)$, K-L I vs. K-L II $($ Hyp $=18.71 \pm 5.81$ vs. $10.65 \pm 3.33 \mu \mathrm{g} / \mathrm{mg}$ w.wt, $p<0.01)$ and K-L II vs. K-L III (Hyp = $10.65 \pm 3.33$ vs. $15.88 \pm 1.43 \mu \mathrm{g} / \mathrm{mg}$ w.wt, $p<0.01$ ) (Figure 4B). Hyp was found to be negatively correlated with Raman biomarkers ColD/F (A1245 cm $\left.-1 / \mathrm{A} 12070 \mathrm{~cm}^{-1}\right)$ and HA/Col $\left(\right.$ A960 $\left.\mathrm{cm}^{-1} / \mathrm{A} 920 \mathrm{~cm}^{-1}\right)$, with rho $=-0.2894(p=0.0485)$ and rho $=-0.3168(p=0.0340)$, respectively (Figure 5). These results suggest that Hyp biochemical content was lower in cartilage samples where both a greater relative disorganization of collagen and bone to collagenous matrix ratio were observed, in the course of OA severity (Figure $2 \mathrm{ColD} / \mathrm{F}$ and $\mathrm{HA} / \mathrm{Col}$, respectively).

\section{Discussion}

$\mathrm{OA}$ is a complex and multifactorial disease characterized by major changes that succinctly consist on the disorganization of the articular cartilage, edema, chondrocyte apoptosis, tissue loss, and subchondral bone changes [2]. Even though structural, cellular, and molecular processes during cartilage degradation have been thoroughly investigated, OA pathogenesis is far from being understood. As such, early diagnosis, biomarkers validation and personalized treatments are still some of its major unmet needs [32,33].

Raman spectroscopy has been previously used to describe the molecular fingerprint of articular cartilage derived from different joint tissues $[15,16,18,19,23]$. However, there is still a lack of consistent studies that can validate the use of Raman signals or derived ratios 
for the detection and follow-up of molecular changes in the onset and progression of OA. For this study, focused on hip OA, we have selected and proposed an optical biomarker panel, based on a previous literature review, considering representative parameters, related with major and minor cartilage ECM components [13].

From the parameters related with GAGs, we demonstrated negative correlations between SGAGs and PGs with radiological OA severity. These were both cross-validated against sGAGs biochemical content, which support the decrease in proteoglycans that occurs in OA cartilage [34]. SGAGs ratio hereby proposed as a candidate biomarker was previously studied by Kumar et al., obtaining similar results regarding the ICRS grading system [18]. It is worth noting that, from all the candidate biomarkers, SGAGs was the only where a significant difference was found between healthy-doubtful OA and moderate radiological grade (K-L 0-I vs. II) (Figure 3). The lack of differences between healthy cartilage samples and those in early stages of OA may be due to compensatory synthesis mechanisms of chondrocytes in response to initial damage [34]. Moreover, SGAGs, being directly related to sulphate groups, has potential in assessing the sulphation loss in the cartilaginous tissue during its degradation [35]. Water content was also found increased, although this was not significant (data not shown).

Considering other major component of cartilage ECM, we have studied the ColD/F parameter, proposed by other authors, to characterize the disorganization of the relative structure of collagen $[17,18]$. This parameter that significantly increased with OA severity, also correlated with K-L grade. The observed increase in the random coil collagen structure signal (i.e., defective collagen), could be indicative of denaturation or metabolic changes in the collagen synthesis process. OA chondrocytes have been described to synthetize type- $X$ collagen in hypertrophic cartilage and type-VI collagen in interterritorial zones [34,36]. These two types of collagen have large non-helical terminal domains, and considerably smaller $\alpha$-helix domains than those of type-II collagen (460 and 200 amino acids respectively, compared to 1000 amino acids) $[37,38]$. Therefore, the increase in the ColD/F parameter could be due to the synthesis of both type- $X$ and -VI collagens.

Although previous studies showed total collagens content to be either increased or not altered during OA, by synthesis/degradation processes [39-42], in our case, Hyp biochemical content significantly decreased with OA severity, which could be related to the stability of type-II collagen triple helix structure domains [43]. Furthermore, the association of this amino acid with the stability of the collagen structure was confirmed, finding a weak, but significant correlation, indicating a greater relative disorganization of the collagen fibers (higher ColD/F values) with a decrease in Hyp residues.

HA/Col showed a negative correlation with Hyp content, indicating a lower relative collagen content with an increasing mineralization, which could be related to nucleation and crystal deposition processes around collagen fibers. The mineralization process could also be favored by a decrease in proteoglycans and sGAGs in cartilage ECM during OA progression $[44,45]$, supported in our case, by a decrease in the SGAGs/HA parameter.

Mineralization and tissue remodeling are processes that occur during OA progression. Basic calcium phosphate (BCP), such as hydroxyapatite (HA), and calcium pyrophosphate dihydrate (CPP) are commonly deposited in OA and aging cartilage and can directly promote the production of catabolic and pro-inflammatory cytokines and enzymes by chondrocytes and synovial cells [46]. The pathogenic mechanism of calcium crystals deposition is still not fully elucidated and calcium-containing crystal deposition diseases are commonly underdiagnosed.

Even though both crystal types have been shown to coexist in cartilage [47], other authors have rarely found them in the same articular tissue (condyle vs. tibial plateau) or zonal distribution (lateral vs. medial compartments) [44]. In our study, we detected the concomitant presence of spectral bands for molecular functional groups associated with both BCP (MGP and MGC) and CPPD, in 68\% of the samples (data not shown). Even though CPPD was present in the majority of samples (87.5\%) (data not shown), its deposition was not correlated with OA severity. 
Indeed, others have demonstrated that in some instances CPPD in cartilage middle zone can accumulate in the absence of cartilage lesions. Although the same authors also reported superficial zone crystal deposition to be linked with cartilage lesions, suggesting an intimate association between metabolically altered and fissured cartilage with crystal nucleation that worsens the tissue mechanical damage [48].

The relatively unique capacity of chondrocytes to produce extracellular inorganic pyrophosphate is linked to the promotion of chondrocalcinosis [49]. In our case, three cases of chondrocalcinosis were confirmed during radiography examination, from which, two samples had the highest CPPD (K-L I) or MGC (K-L III) ratios (Figure 3), although these could also be related to other degradation processes associated with age [50].

On the other hand, only HA-related signals (phosphate-MGP and carbonate-MGC) showed an increasing trend with OA severity, supported by a significant correlation for the latest. A relation between $\mathrm{BCP}$ crystals presence in the synovial fluid of patients with radiologic knee OA has previously been shown [51]. BCP crystals have also been associated with secondary forms of arthropathies or calcific periarthritis [46]. In our cohort, we found one sample, that concomitantly presented one of the highest MGC and CPPD ratios (K-L IV, Figure 3), to be a diagnosed case of psoriatic arthritis. These results support further investigation on the potential of RS in the diagnosis of calcium crystal deposition musculoskeletal diseases, complemented with other techniques, such as histology and polarized light microscopy, in order to elucidate the contribution of crystals deposition in cartilage degradation and remodeling processes [52].

Finally, when considering ECM minor components, such as lipids, this is the first study that reports IL for cartilage molecular characterization, based on Raman peaks previously described for other tissues [53,54]. We observed a significant increase of the IL parameter, for moderate and severe radiological hip OA samples, supported by a positive correlation. These results could be related to an accumulation of lipids in OA cartilage and concomitant protein low abundance due to ECM proteolysis, as described by mass spectrometry $[55,56]$. Others have shown in cellular studies using chondrocytes an increase in lipid deposition, by considering other Raman signals attributed to lipids $\left(\sim 1304 \mathrm{~cm}^{-1}\right)$ with the advancement of OA [28]. Nonetheless, more studies are needed to elucidate the role of lipid deposition in OA progression. Other variable to have into account is body mass index (BMI), which has been shown to influence on the quantification of the peak $\sim 1450 \mathrm{~cm}^{-1}$ [54]. Being obesity a risk factor for OA, BMI values could be considered in future analyses. Unfortunately, these data were not available for the current study.

Even though this study sheds light in the potential of optical biomarkers for OA diagnosis, it presents some limitations. This study constitutes the biggest cohort on hip-OA with RS to date, although due to lack of access to radiographies from samples derived from healthy tissue, only six samples were available. Moreover, some of these samples, even though found no radiological signs of OA, already presented some macroscopically identified lesions. In contrast and due to access derived from replacement surgeries, an over-representation of K-L IV grade samples was obtained.

Another limitation was that cartilage samples were not always obtained from the same compartment of the hip and thus our cohort comprises samples from both load and non-load areas that have been associated with different RS profiles [17]. Nevertheless, we conducted a comparison between RS parameters in cartilage derived from lesion and adjacent sites and we could only find significant differences for SGAGs and HA/Col in K-L II samples (data not shown), which can be an indicative that molecular alterations could already be predicted in adjacent and macroscopically intact cartilage. This finding is noteworthy when considering future translation of RS for OA diagnosis in clinical settings, already being tested in vivo under laser coupling with fiber optic probe systems $[15,57,58]$.

In summary, described findings in this study support the association of the different optical biomarker candidates with OA-cartilage molecular changes that include, a decrease in proteoglycans that can be related to the action of aggrecanases and metalloproteases (MMP) and a lower expression of aggrecan by chondrocytes [34,59], sulphation loss [40], 
alterations or denaturation of the collagen network $[39,60]$, and nucleation of calcium crystals around altered collagen fibers [45,61].

\section{Conclusions}

We have successfully described the molecular fingerprint of human articular cartilage derived from the femoral head of healthy and radiological OA patients. Our results support SGAGs, PGs, and ColD/F as optical OA biomarker candidates, obtaining significant correlations with K-L grade as gold standard and cross-validated against sGAGs and Hyp biochemical contents. IL and calcium-related signals (MGP, MCP, and CPPD) have also shown potential and need further validation for their role in elucidating tissue remodeling and mineralization processes during OA. Finally, this study supports Raman spectroscopy application as a diagnostic complementary tool for hip OA.

Supplementary Materials: The following are available online at https://www.mdpi.com/2075-441 8/11/3/546/s1, Figure S1: Example of area measurement by MagicPlot software, in wavenumber range 1045-1080 $\mathrm{cm}^{-1}$, of a Raman spectrum from an arbitrary cartilage sample.

Author Contributions: J.M. and F.J.B. conceived and designed the study. P.C.-B. and N.O. performed the measurements. P.C.-B., V.B.-B., S.P.-D., and J.M. performed the analysis and the interpretation of data. P.C.-B. and J.M. drafted the article. All authors have read and agreed to the published version of the manuscript.

Funding: This work was financially supported by INTERREG V-A POCTEP Program through European FEDER funds (0245_IBEROS_1_E), AE CICA-INIBIC (ED431E 2018/03) and IN607A2017/11 grants, funded by the Consellería de Cultura e Ordenación Universitaria, Xunta de Galicia. The Biomedical Research Networking Center (CIBER) is an initiative from the Instituto de Salud Carlos III (ISCIII)—Ministerio de Ciencia e Innovación (MICINN).

Institutional Review Board Statement: The study was conducted in accordance with the guidelines of the Declaration of Helsinki and the study protocol was approved by the Galician Research Ethics Committee-CAEIG (Project Registry Code: 2018/268).

Informed Consent Statement: Human cartilage samples described belong to the Sample Collection for Research on Rheumatic Diseases authorized by the Galician Research Ethics Committee (CAEIG) with registry code 2013/107 and inscribed in the National Registry of Biobanks-Collections Section (Code C.0000424). The patients have signed an informed consent agreement form prior to collection.

Acknowledgments: We thank Ezequiel Vázquez from the IR-Raman division of RIAIDT, Universidad de Santiago de Compostela, for technical advice. We acknowledge Xabi González (UVigo), Graciela Arrojo and María Barbeito (FPNS) for administrative support.

Conflicts of Interest: The authors declare no conflict of interest. The funders had no role in the design of the study, collection, analyses, data interpretation, or in the writing of the manuscript, or in the decision to publish the results.

\section{References}

1. Yuan, X.L.; Meng, H.Y.; Wang, Y.C.; Peng, J.; Guo, Q.Y.; Wang, A.Y.; Lu, S.B. Bone-Cartilage Interface Crosstalk in Osteoarthritis: Potential Pathways and Future Therapeutic Strategies. Osteoarthr. Cartil. 2014, 22, 1077-1089. [CrossRef] [PubMed]

2. Bay-Jensen, A.C.; Hoegh-Madsen, S.; Dam, E.; Henriksen, K.; Sondergaard, B.C.; Pastoureau, P.; Qvist, P.; Karsdal, M.A. Which Elements Are Involved in Reversible and Irreversible Cartilage Degradation in Osteoarthritis? Rheumatol. Int. 2010, 30, 435-442. [CrossRef]

3. Kraus, V.B.; Blanco, F.j; Englund, M.; Karsdal, M.A.; Lohmander, L.S. Call for Standardized Definitions of Osteoarthritis and Risk Stratification for Clinical Trials and Clinical Use. Osteoarthr. Cartil. 2015, 23, 1233-1241. [CrossRef] [PubMed]

4. Hunter, D.J.; Guermazi, A.; Lo, G.H.; Grainger, A.J.; Conaghan, P.G.; Boudreau, R.M.; Roemer, F.W. Evolution of Semi-Quantitative Whole Joint Assessment of Knee OA: MOAKS (MRI Osteoarthritis Knee Score). Osteoarthr. Cartil. 2011, 19, 990-1002. [CrossRef]

5. Kellgren, J.; Lawrence, J. Radiological Assessment of Osteo-Arthrosis. Ann. Rheum. Dis. 1957, 16, 494-502. [CrossRef] [PubMed]

6. van der Kraan, P.M.; Berenbaum, F.; Blanco, F.J.; Cosimo, D.B.; Lafeber, F.; Hauge, E.; Higginbottom, A.; Ioan-Facsinay, A.; Loughlin, J.; Meulenbelt, I.; et al. Translation of Clinical Problems in Osteoarthritis into Pathophysiological Research Goals. RMD Open 2016, 2, e000224. [CrossRef] [PubMed] 
7. Butler, H.J.; Ashton, L.; Bird, B.; Cinque, G.; Curtis, K.; Dorney, J.; Esmonde-White, K.; Fullwood, N.J.; Gardner, B.; Martin-Hirsch, P.L.; et al. Using Raman Spectroscopy to Characterize Biological Materials. Nat. Protoc. 2016, 11, 664-687. [CrossRef]

8. Gautam, R.; Samuel, A.; Sil, S.; Chaturvedi, D.; Dutta, A.; Ariese, F.; Umapathy, S. Raman and Mid-Infrared Spectroscopic Imaging: Applications and Advancements. Curr. Sci. 2015, 108, 341-356.

9. Pavlou, E.; Zhang, X.; Wang, J.; Kourkoumelis, N. Raman Spectroscopy for the Assessment of Osteoarthritis. Ann. Jt. 2018, 3, 83. [CrossRef]

10. Hosu, C.D.; Moisoiu, V.; Stefancu, A.; Antonescu, E.; Leopold, L.F.; Leopold, N.; Fodor, D. Raman Spectroscopy Applications in Rheumatology. Lasers Med. Sci. 2019, 34, 827-834. [CrossRef] [PubMed]

11. Albro, M.B.; Bergholt, M.S.; St-Pierre, J.P.; Vinals Guitart, A.; Zlotnick, H.M.; Evita, E.G.; Stevens, M.M. Raman Spectroscopic Imaging for Quantification of Depth-Dependent and Local Heterogeneities in Native and Engineered Cartilage. NPJ Regen. Med. 2018, 3, 1-11. [CrossRef] [PubMed]

12. Bergholt, M.S.; Serio, A.; Albro, M.B. Raman Spectroscopy: Guiding Light for the Extracellular Matrix. Front. Bioeng. Biotechnol. 2019, 7, 303. [CrossRef]

13. Casal-Beiroa, P.; González, P.; Blanco, F.J.; Magalhães, J. Molecular Analysis of the Destruction of Articular Joint Tissues by Raman Spectroscopy. Expert Rev. Mol. Diagn. 2020, 20, 789-802. [CrossRef] [PubMed]

14. Casal-Beiroa, P.; Blanco, F.J.; Magalhães, J. Raman spectroscopy for cartilage damage severity, degradation and repair assessment. In Avances de la Bioingeniería Para el Envejecimiento Saludable; González, P., Ed.; Universidade de Vigo: Vigo, Spain, 2020; pp. 43-54. ISBN 978-84-8158-832-3.

15. Esmonde-White, K.A.; Esmonde-White, F.W.L.; Morris, M.D.; Roessler, B.J. Fiber-Optic Raman Spectroscopy of Joint Tissues. Analyst 2011, 136, 1675-1685. [CrossRef]

16. Richardson, W.; Wilkinson, D.; Wu, L.; Petrigliano, F.; Dunn, B.; Evseenko, D. Ensemble Multivariate Analysis to Improve Identification of Articular Cartilage Disease in Noisy Raman Spectra. J. Biophotonics 2015, 8, 555-566. [CrossRef] [PubMed]

17. Takahashi, Y.; Sugano, N.; Takao, M.; Sakai, T.; Nishii, T.; Pezzotti, G. Raman Spectroscopy Investigation of Load-Assisted Microstructural Alterations in Human Knee Cartilage: Preliminary Study into Diagnostic Potential for Osteoarthritis. J. Mech. Behav. Biomed. Mater. 2014, 31, 77-85. [CrossRef]

18. Kumar, R.; Grønhaug, K.M.; Afseth, N.K.; Isaksen, V.; de Lange Davies, C.; Drogset, J.O.; Lilledahl, M.B. Optical Investigation of Osteoarthritic Human Cartilage (ICRS Grade) by Confocal Raman Spectroscopy: A Pilot Study. Anal. Bioanal. Chem. 2015, 407, 8067-8077. [CrossRef] [PubMed]

19. Kunstar, A.; Leijten, J.; van Leuveren, S.; Hilderink, J.; Otto, C.; van Blitterswijk, C.A.; Karperien, M.; van Apeldoorn, A.A. Recognizing Different Tissues in Human Fetal Femur Cartilage by Label-Free Raman Microspectroscopy. J. Biomed. Opt. 2012, 17, 116012. [CrossRef] [PubMed]

20. de Souza, R.A.; Xavier, M.; Mangueira, N.M.; Santos, A.P.; Pinheiro, A.L.B.; Villaverde, A.B.; Silveira, L. Raman Spectroscopy Detection of Molecular Changes Associated with Two Experimental Models of Osteoarthritis in Rats. Lasers Med. Sci. 2014, 29 , 797-804. [CrossRef]

21. Gamsjaeger, S.; Klaushofer, K.; Paschalis, E.P. Raman Analysis of Proteoglycans Simultaneously in Bone and Cartilage. J. Raman Spectrosc. 2014, 45, 794-800. [CrossRef]

22. Eberhardt, K.; Stiebing, C.; Matthäus, C.; Schmitt, M.; Popp, J. Advantages and Limitations of Raman Spectroscopy for Molecular Diagnostics: An Update. Expert Rev. Mol. Diagn. 2015, 15, 773-787. [CrossRef] [PubMed]

23. Lim, N.S.J.; Hamed, Z.; Yeow, C.H.; Chan, C.; Huang, Z. Early Detection of Biomolecular Changes in Disrupted Porcine Cartilage Using Polarized Raman Spectroscopy. J. Biomed. Opt. 2011, 16, 017003. [CrossRef]

24. Movasaghi, Z.; Rehman, S.; Rehman, I.U. Raman Spectroscopy of Biological Tissues. Appl. Spectrosc. Rev. 2007, 42, 493-541. [CrossRef]

25. Buchwald, T.; Niciejewski, K.; Kozielski, M.; Szybowicz, M.; Siatkowski, M.; Krauss, H. Identifying Compositional and Structural Changes in Spongy and Subchondral Bone from the Hip Joints of Patients with Osteoarthritis Using Raman Spectroscopy. J. Biomed. Opt. 2012, 17, 017007. [CrossRef] [PubMed]

26. Khan, A.F.; Awais, M.; Khan, A.S.; Tabassum, S.; Chaudhry, A.A.; Rehman, I.U. Raman Spectroscopy of Natural Bone and Synthetic Apatites. Appl. Spectrosc. Rev. 2013, 48, 329-355. [CrossRef]

27. Levillain, A.; Boulocher, C.; Kaderli, S.; Viguier, E.; Hannouche, D.; Hoc, T.; Magoariec, H. Meniscal Biomechanical Alterations in an ACLT Rabbit Model of Early Osteoarthritis. Osteoarthr. Cartil. 2015, 23, 1186-1193. [CrossRef] [PubMed]

28. Kumar, R.; Singh, G.P.; Grønhaug, K.M.; Afseth, N.K.; de Lange Davies, C.; Drogset, J.O.; Lilledahl, M.B. Single Cell Confocal Raman Spectroscopy of Human Osteoarthritic Chondrocytes: A Preliminary Study. Int. J. Mol. Sci. 2015, 16, 9341-9353. [CrossRef]

29. Gunasekaran, S.; Anbalagan, G.; Pandi, S. Raman and Infrared Spectra of Carbonates of Calcite Structure. J. Raman Spectrosc. 2006, 37, 892-899. [CrossRef]

30. Wang, D.; Hamm, L.M.; Bodnar, R.J.; Dove, P.M. Raman Spectroscopic Characterization of the Magnesium Content in Amorphous Calcium Carbonates. J. Raman Spectrosc. 2012, 43, 543-548. [CrossRef]

31. Awonusi, A.; Morris, M.D.; Tecklenburg, M.M.J. Carbonate Assignment and Calibration in the Raman Spectrum of Apatite. Calcif. Tissue Int. 2007, 81, 46-52. [CrossRef]

32. Fernández-Puente, P.; Mateos, J.; Fernández-Costa, C.; Oreiro, N.; Fernández-López, C.; Ruiz-Romero, C.; Blanco, F.J. Identification of a Panel of Novel Serum Osteoarthritis Biomarkers. J. Proteome Res. 2011, 10, 5095-5101. [CrossRef] [PubMed] 
33. Lourido, L.; Ayoglu, B.; Fernández-Tajes, J.; Oreiro, N.; Henjes, F.; Hellström, C.; Schwenk, J.M.; Ruiz-Romero, C.; Nilsson, P.; Blanco, F.J. Discovery of Circulating Proteins Associated to Knee Radiographic Osteoarthritis. Sci. Rep. 2017, 7, 137. [CrossRef]

34. Martel-Pelletier, J.; Boileau, C.; Pelletier, J.P.; Roughley, P.J. Cartilage in Normal and Osteoarthritis Conditions. Best Pract. Res. Clin. Rheumatol. 2008, 22, 351-384. [CrossRef]

35. Bayliss, M.T.; Osborne, D.; Woodhouse, S.; Davidson, C. Sulfation of Chondroitin Sulfate in Human Articular Cartilage: The Effect of Age, Topographical Position, and Zone of Cartilage on Tissue Composition. J. Biol. Chem. 1999, 274, 15892-15900. [CrossRef]

36. Söder, S.; Hambach, L.; Lissner, R.; Kirchner, T.; Aigner, T. Ultrastructural Localization of Type VI Collagen in Normal Adult and Osteoarthritic Human Articular Cartilage. Osteoarthr. Cartil. 2002, 10, 464-470. [CrossRef]

37. Gelse, K. Collagens-Structure, Function, and Biosynthesis. Adv. Drug Deliv. Rev. 2003, 55, 1531-1546. [CrossRef] [PubMed]

38. Rieppo, L.; Töyräs, J.; Saarakkala, S. Vibrational Spectroscopy of Articular Cartilage. Appl. Spectrosc. Rev. 2017, 52, 249-266. [CrossRef]

39. Buckwalter, J.A.; Mankin, H.J.; Grodzinsky, A.J. Articular Cartilage and Osteoarthritis. Instr. Course Lect. 2005, 54, 465-480.

40. Lorenzo, P.; Bayliss, M.T.; Heinegård, D. Altered Patterns and Synthesis of Extracellular Matrix Macromolecules in Early Osteoarthritis. Matrix Biol. 2004, 23, 381-391. [CrossRef] [PubMed]

41. Maldonado, M.; Nam, J. The Role of Changes in Extracellular Matrix of Cartilage in the Presence of Inflammation on the Pathology of Osteoarthritis. Biomed. Res. Int. 2013, 2013, 1-10. [CrossRef] [PubMed]

42. Pearle, A.D.; Warren, R.F.; Rodeo, S.A. Basic Science of Articular Cartilage and Osteoarthritis. Clin. Sports Med. 2005, 24, 1-12. [CrossRef]

43. Weis, M.A.; Hudson, D.M.; Kim, L.; Scott, M.; Wu, J.-J.; Eyre, D.R. Location of 3-Hydroxyproline Residues in Collagen Types I, II, III, and V/XI Implies a Role in Fibril Supramolecular Assembly. J. Biol. Chem. 2010, 285, 2580-2590. [CrossRef] [PubMed]

44. Nguyen, C.; Bazin, D.; Daudon, M.; Chatron-Colliet, A.; Hannouche, D.; Bianchi, A.; Côme, D.; So, A.; Busso, N.; Lioté, F.; et al. Revisiting Spatial Distribution and Biochemical Composition of Calcium-Containing Crystals in Human Osteoarthritic Articular Cartilage. Arthritis Res. Ther. 2013, 15, R103. [CrossRef] [PubMed]

45. Yan, J.; Qin, W.; Xiao, B.; Wan, Q.; Tay, F.R.; Niu, L.; Jiao, K. Pathological Calcification in Osteoarthritis: An Outcome or a Disease Initiator? Biol. Rev. 2020, 9. [CrossRef]

46. McCarthy, G.M.; Dunne, A. Calcium Crystal Deposition Diseases-Beyond Gout. Nat. Rev. Rheumatol. 2018, 14, 592-602. [CrossRef]

47. Durcan, L.; Bolster, F.; Kavanagh, E.C.; McCarthy, G.M. The Structural Consequences of Calcium Crystal Deposition. Rheum. Dis. Clin. N. Am. 2014, 40, 311-328. [CrossRef]

48. Muehleman, C.; Li, J.; Aigner, T.; Rappoport, L.; Mattson, E.; Hirschmugl, C.; Masuda, K.; Rosenthal, A.K. Association between Crystals and Cartilage Degeneration in the Ankle. J. Rheumatol. 2008, 35, 1108-1117. [CrossRef] [PubMed]

49. Pay, S.; Terkeltaub, R. Calcium Pyrophosphate Dihydrate and Hydroxyapatite Crystal Deposition in the Joint: New Developments Relevant to the Clinician. Curr. Rheumatol. Rep. 2003, 5, 235-243. [CrossRef] [PubMed]

50. Mitsuyama, H.; Healey, R.M.; Terkeltaub, R.A.; Coutts, R.D.; Amiel, D. Calcification of Human Articular Knee Cartilage Is Primarily an Effect of Aging Rather than Osteoarthritis. Osteoarthr. Cartil. 2007, 15, 559-565. [CrossRef]

51. Halverson, P.B.; McCarty, D.J. Patterns of Radiographic Abnormalities Associated with Basic Calcium Phosphate and Calcium Pyrophosphate Dihydrate Crystal Deposition in the Knee. Ann. Rheum. Dis. 1986, 45, 603-605. [CrossRef]

52. Fuerst, M.; Bertrand, J.; Lammers, L.; Dreier, R.; Echtermeyer, F.; Nitschke, Y.; Rutsch, F.; Schäfer, F.K.W.; Niggemeyer, O.; Steinhagen, J.; et al. Calcification of Articular Cartilage in Human Osteoarthritis. Arthritis Rheum. 2009, 60, $2694-2703$. [CrossRef] [PubMed]

53. Valdés, R.; Stefanov, S.; Chiussi, S.; López-Alvarez, M.; González, P. Pilot Research on the Evaluation and Detection of Head and Neck Squamous Cell Carcinoma by Raman Spectroscopy. J. Raman Spectrosc. 2014, 45, 550-557. [CrossRef]

54. Ding, H.; Dupont, A.W.; Singhal, S.; Scott, L.D.; Guha, S.; Younes, M.; Ye, Y.; Bi, X. Effect of Physiological Factors on the Biochemical Properties of Colon Tissue-An in Vivo Raman Spectroscopy Study. J. Raman Spectrosc. 2017, 48, 902-909. [CrossRef]

55. Rocha, B.; Ruiz-Romero, C.; Blanco, F.J. Mass Spectrometry Imaging: A Novel Technology in Rheumatology. Nat. Rev. Rheumatol. 2017, 13, 52-63. [CrossRef] [PubMed]

56. Cillero-Pastor, B.; Eijkel, G.; Kiss, A.; Blanco, F.J.; Heeren, R.M.A. Time-of-Flight Secondary Ion Mass Spectrometry-Based Molecular Distribution Distinguishing Healthy and Osteoarthritic Human Cartilage. Anal. Chem. 2012, 84, 8909-8916. [CrossRef] [PubMed]

57. Sarin, J.K.; Te Moller, N.C.R.; Mancini, I.A.D.; Brommer, H.; Visser, J.; Malda, J.; van Weeren, P.R.; Afara, I.O.; Töyräs, J. Arthroscopic near Infrared Spectroscopy Enables Simultaneous Quantitative Evaluation of Articular Cartilage and Subchondral Bone in Vivo. Sci. Rep. 2018, 8, 13409. [CrossRef] [PubMed]

58. Cordero, E.; Latka, I.; Matthäus, C.; Schie, I.W.; Popp, J. In-Vivo Raman Spectroscopy: From Basics to Applications. J. Biomed. Opt. 2018, 23, 071210. [CrossRef]

59. Aigner, T.; McKenna, L. Molecular Pathology and Pathobiology of Osteoarthritic Cartilage. Cell. Mol. Life Sci. 2002, 59, 5-18. [CrossRef] 
60. Hollander, A.P.; Heathfield, T.F.; Webber, C.; Iwata, Y.; Bourne, R.; Rorabeck, C.; Poole, A.R. Increased Damage to Type II Collagen in Osteoarthritic Articular Cartilage Detected by a New Immunoassay. J. Clin. Investig. 1994, 93, 1722-1732. [CrossRef] [PubMed]

61. Rýglová, Š.; Braun, M.; Suchý, T. Collagen and Its Modifications-Crucial Aspects with Concern to Its Processing and Analysis. Macromol. Mater. Eng. 2017, 302, 1600460. [CrossRef] 